\title{
Development of a memories vocabulary (MemVOC) for food products using coffee as a model
}

\author{
Adan CABAL-PRIETO ${ }^{1}$ (D), Gabriela TEODORO-BERNABÉ ${ }^{1}$ (D) , \\ Cecilia CORIA-RINCÓN ${ }^{1}$ (D) , Lucia SÁNCHEZ-ARELLANO ${ }^{1}$ (D), Lorena Guadalupe RAMÓN-CANUL (D), $^{-}$ \\ Jesús RODRÍGUEZ-MIRANDA ${ }^{3} \mathbb{D}$, Witoon PRINYAWIWATKUL ${ }^{4}$ (D) , José Manuel JUÁREZ-BARRIENTOS ${ }^{5}$ (D) , \\ José Andrés HERRERA-CORREDOR ${ }^{6 *}$ (D), Emmanuel de Jesús RAMÍREZ-RIVERA ${ }^{7 * ~(D)}$
}

\begin{abstract}
Multiple references in sensory science indicate that foods evoke memories during consumption, however, research regarding those memories is still limited. The objective of this study was to develop a vocabulary and implement it in a memories vocabulary related to food as a complement for the evaluation of sensory attributes and emotions, using coffee as a model. The memories vocabulary was generated with a series of successive studies that involved assigning positive and negative memories to different food groups and applying mathematical algorithms (WordCountAna and Factorial Approach) and contrasting memories with the scientific literature. Subsequently, the vocabulary was used to determine the profile of memories and their association with sensory attributes and emotions in coffee samples evaluated by trained judges and consumers. The memories vocabulary consisted of a total of 14 and 12 positive and negative memories terms, respectively. The vocabulary of memories was used in a similar way by both panels allowing them to differentiate between artisanal and industrial coffees. The memories vocabulary of the coffees showed a positive association with sensory attributes and emotions, thus achieving a more robust explanation of the samples used in the research.
\end{abstract}

Keywords: artisan and industrial coffees; emotions; food-related memories; sensory attributes.

Practical Application: The memories vocabulary can help to understand the impact of food on the consumer's memories, this allows the generation of a new paradigm for a comprehensive characterization of food including sensory characteristics, memories, and emotions. Our proposal is to use a memories vocabulary to help respondents retrieve those memories in a systematic way that can be further analyzed using a diversity of statistical techniques.

\section{Introduction}

Market demand and consumer preferences are constantly evolving (Braun-Endo \& Brás-Roque, 2017). In order to deal with changes in market needs, the food industry has focused on finding sensory attributes that have an impact on consumer preference (Ramírez-Rivera et al., 2018) and purchase intent. However, sensory attributes of food products are not the only determining factor in choosing a food by consumer, and emotions can also influence purchase intent (Köster, 2003; King \& Meiselman, 2010; Jiang et al., 2014). Currently, the field of sensometry has developed techniques for the evaluation of sensory attributes and emotions in different foods such as wines, freshness of chicken breast, tortillas, among others (Jose-Coutinho et al., 2015; Oliveira e Silva et al., 2020; Santiago-Cruz et al., 2021), and food neophobia scales have even been developed (McKenzie et al., 2021). According to Köster (2003) most sensory research is based on perception and scarcely on the use of memories in the choice of food. Despite these efforts, a gap still exists between sensory attributes and emotions that has not yet been fully explored. In this regard memories that are considered as prominent signals and lived in the mind of the consumer can influence their attitudes, emotions, and purchase intent (Herz \& Brunk, 2017). This void is related to the memories that are the autobiographical events that a person experiences (e. g., places, events, among others) (Sester et al., 2013). According to Mark et al. (1992) and Navarro Bravo et al. (2008), memories are divided into extended (those that last for more than one day, such as childhood), categorical (those that refer to repeated actions such as Christmas) and specific (those specific moments in a specific space and time such as celebrations). They can also be classified as negative (which refer to traumatic events) or positive (that are happy and pleasant memories of great impact; Manzanero et al. (2015). According to Lin \& Mao (2015), food products can generate

\footnotetext{
Received 17 June, 2021

Accepted 03 Nov., 2021

${ }^{1}$ Tecnológico Nacional de México, Campus Huatusco, Huatusco, Veracruz, México

${ }^{2}$ Tecnológico Nacional de México, Campus Mérida, Mérida, Yucatán, México

${ }^{3}$ Tecnológico Nacional de México, Campus Tuxtepec, Tuxtepec, Oaxaca, México

${ }^{4}$ School of Nutrition and Food Sciences, Louisiana State University Agricultural Center, Baton Rouge, LA, EUA

${ }^{5}$ Universidad del Papaloapan, Campus Loma Bonita, Loma Bonita, Oaxaca, México

${ }^{6}$ Colegio de Postgraduados, Campus Córdoba, Amatlán de los Reyes, Veracruz, México

${ }^{7}$ Tecnológico Nacional de México, Campus Zongolica, Zongolica, Veracruz, México

*Corresponding authors: ejramirezrivera@zongolica.tecnm.mx, jandreshc@colpos.mx
} 
different memories, as other objects do (e.g., postcard, t-shirt, among others) due to their sensory characteristics which can influence purchase intent (Vidal et al., 2013). A clear example is the evaluation of the odors that travel through the nostrils to the olfactory epithelium where they are then decoded in the orbitofrontal cortex and reinforced by the functions of the amygdala to provide information about food (Gierczynski et al., 2011; Broche-Pérez et al., 2016). This process results in complex semantic and cognitive construct through the relationship of memories about a food and the experiences stored in the consumer's memories (Bettman, 1979; Morin-Audebrand et al., 2009). Currently, research using sensory memories has been focused on aspects such as texture of food (Mojet \& Köster, 2005), flavor and aromas (Morin-Audebrand et al., 2009), development of food souvenirs (Lin \& Mao, 2015), determination of false memories in preference, among others (Howe et al., 2017; Aiello et al., 2018). However, these studies do not specifically indicate the memories generated by the tested food products. Although in the field of psychology there are different techniques to evaluate memories (e.g., autobiographical memories test, face and feelings test, among others), these cannot be easily adapted to the sensory evaluation context due to their execution time and result interpretation (Ricarte et al., 2013). Therefore, there is a need to generate a vocabulary of memories that can be integrated with different sensory techniques (e. g., CheckAll-The-Apply-CATA, among others) to determine a profile of memories generated by food products during consumption and that can influence consumer decision-making (Vidal et al., 2018; Shaw \& Bagozzi, 2018). The objective of this research was to develop a vocabulary and implement it in a memories vocabulary related to food as a complement for the evaluation of sensory attributes and emotions, using coffee as a model.

\section{Materials and methods}

The study was carried out in two successive phases. Phase 1) generation of memories vocabulary using an online questionnaire. Phase 2) application of the vocabulary of memories for the generation of a profile of memories in artisanal and industrial coffees.

\subsection{Phase 1: generation of food-related memories vocabulary}

To carry out this phase, the following steps were followed: Step 1) Different food groups were considered: Group 1: dairy, Group 2: fruits and vegetables, Group 3: confectionery, Group 4: cereals, Group 5: meat, Group 6: seafood (fish, shrimp), Group 7: eggs, Group 8: soups, Group 9: drinks (coffee, chocolates, soft drinks), Group 10: alcoholic beverages (wines, beers) and Group 11: meals. These foods were also considered in the research of Laguna et al. (2020) who evaluated the impact of COVID-19 on food priorities through an online survey and by Paixão et al. (2020), who evaluated alcoholic and non-alcoholic beverages. From each food group, five digital images were captured using a Panasonic Lumix camera, model DMC-TZ3 with fixed lighting for each shot (Baima \& Ribotta, 2019). The use of images for sensory studies using online questionnaires is a valuable tool to find differences among products (Spinelli et al., 2015; SantiagoCruz et al., 2021). The criteria for selecting the images were:
1) they must be representative of their respective food group, 2) company labels were removed to avoid bias on consumer response, and 3) the images were taken on a white background. Step 2) A questionnaire was designed using the Google ${ }^{\circledast}$ Forms tool for collecting memories words associated with each food group mentioned in Step 1. The access link to the questionnaire was distributed using social networks and instant messaging applications where consumers $(N=361)$ were asked to assign positive or negative words or memories to each food group from step1. Criteria for consumer selection were as follows: 1) availability to answer the survey; 2) consumers aged over 18 years, 3) a middle school education level was required for vocabulary generation. Responses from consumers whom did not meet these conditions were not included in the data analysis. It was indicated to respondents that positive memories are events that generate happiness and negative memories are traumatic events (Manzanero et al., 2015). The purpose was to allow consumers answering the questionnaire to have in mind what was considered a positive and negative memories in the context of the study. The Free Sorting Task (FST) sensory technique was used to generate the vocabulary of memories as follows: each consumer observed the image of a food and then assigned memory words according to their personal experiences. This technique was used as it eliminates biases due to use of a word list (Mahieu et al., 2020). Consumers were also instructed to keep positive and negative memories words short (between 1 to 5 compound words) to facilitate statistical treatment (Kostov et al., 2014). Data were organized in a matrix with $i$ rows and $j$ columns, where each row $i$ corresponded to each food group $(i=11)$ and column $j$ corresponded to consumers $(j=361$ consumers from different parts of Mexico). Each consumer $j$ assigned qualitative variables (memories words) with $K j$ categories, where $K j$ is the memory to each food group. The labeling of each category is the sequence of words associated with each of the Kj groups (Cadoret et al., 2009). According to Blancher et al. (2012) and Mahieu et al. (2021), the evaluation of a number of products between 8 and 15 with a range of evaluations between $10-118$ or using more than 60 consumers are sufficient to obtain reliable results using the FST technique, since, when less than 50 consumers are used fewer consensual words can be obtained (Kostov et al., 2014). Similarly, the number of consumers surveyed in this study was higher than those used in the research by King \& Meiselman (2010) whom used 305 people for the identification, categorization and selection phases in the development of the vocabulary of emotions. Step 3) The memories vocabulary validation was carried out in two ways: 1) statistical approach: the fast (Factorial Approach for Sorting Task data) and WordCountAna (WordCount based methods Analysis) functions (for textual analysis) by Cadoret et al. (2009) and Kostov et al. (2014) were used for determining probability values. Memories with probability values less than 0.05 were retained. 2) searching if the words of selected memories $(p<0.05)$, mentions equal to or higher than 3 (Perrin et al., 2008; Kostov et al., 2014) and which had been reported in the scientific literature referring to the field of psychology. Once the vocabulary was defined according to the previous ways, results between the trained panel and consumers as well as the correlation with data on sensory attributes and emotions were compared for validation. 


\subsection{Phase 2: application of the vocabulary of memories in coffees: characterization and correlation between memories, sensory attributes, and emotions evaluated by the trained panel and consumers}

The objective of this phase was to identify how trained judges and consumers use the memories vocabulary to characterize coffee samples as well as its relationship with sensory attributes and emotions at the trained panel and consumers' level. Coffee was used as a stimulus due to its sensory complexity and the experiences it generates (Bhumiratana et al., 2019). Additionally, coffee is very well known worldwide making it an excellent candidate to serve as a model for the development of our memories vocabulary as it is very probable consumers to have memories associated to this product. Also, the geographical region where this study was conducted (with the trained panel), is actually a coffee production region. The following steps were carried out: Step 1) six coffee samples were evaluated $(n=$ three artisan coffees [AC1, AC2 and $\mathrm{AC} 3]$ and $n=$ three industrial coffees [IC1, IC2 and IC3]). Artisanal and industrialized coffees were included in the study to find the differences in the memories generated by both types of coffee and because of the high demand for both types of coffees (Favalli et al., 2013). The artisan coffees were acquired from artisan producers and industrialized coffees from convenience stores in the Huatusco region, Veracruz, Mexico. The artisan coffees were prepared as follows: green coffee was prepared according to the guidelines of the ISO standard 6668 (International Organization for Standardization, 2008). Subsequently, the green coffee was roasted following the protocols indicated by the Specialty Coffee Association of America (2009) to get a medium profile roasted coffee. The evaluation of sample coffee was carried out in porcelain cups of $150 \mathrm{~mL}$ identified with a three-digit code as indicated in the Specialty Coffee Association of America (2009) and Ramírez-Rivera et al. (2021). Coffee cupping was performed in porcelain cups. A sample of 8 grams of ground coffee was placed in the cup and $150 \mathrm{~mL}$ hot water $\left(93 \pm 5^{\circ} \mathrm{C}\right)$ was poured. The grounds were allowed to steep for 3 minutes. After this time, the foam layer and particles of the coffee sample were manually removed so it could be evaluated at 40 $\pm 5^{\circ} \mathrm{C}$ by the panelists Specialty Coffee Association of America (2009). The industrial coffees were prepared according to the specifications indicated on package label. Step 2) A trained panel and a consumer panel were formed. The trained panel included nine panelists (five men and four women with an age range between 23 and 49 years old) with more than five years of experience in the evaluation of coffee and they have participated in other studies evaluating a diversity of coffee varieties and coffee based food products. Panelists were recruited from the Instituto Tecnológico Superior de Huatusco, Veracruz, Mexico. Consumers (99 people aged 25 to 50 years) were used in the study taking into account their performance in terms of discrimination from previous studies (Worch et al., 2010). Panelists and consumers were selected according to ISO standard 8586-1 (International Organization for Standardization, 1993) and ISO standard 11035 (International Organization for Standardization, 1994). In the first step, the availability and motivation of each person to participate in the project, daily frequency of coffee consumption and no aversion towards it (ISO standard 8586-1, International Organization for Standardization, 1993) were verified. In the second step, subjects were screened through the application of basic taste tests, recognition of aromas (ISO standard 5496, International Organization for Standardization, 2005), triangular discrimination tests (ISO standard 4120, International Organization for Standardization, 2004c) and duo-trio (ISO standard 10399, International Organization for Standardization, 2004a) test. In the third step, the selection was made from the people who made up each test based on their results obtained from the second stage. For this purpose, the Sequential Analysis with triangle technique was performed (ISO standard 16820, International Organization for Standardization, 2004b) with the following parameters: $\mathrm{p} 0$ $=0.30, \mathrm{p} 1=0.70, \alpha=0.10$ and $\beta=0.10$ ). Step 3) Both panels evaluated aroma (Sweet, Caramel, Chocolate, Herbal, Walnut, Burnt, Woody, Cinnamon, Earthy, Coffee peel, Cherry, Moisture, Spicy and Pineapple), taste (Acidic Sweet, Bitter) and flavor (Fruity, Cinnamon, Caramelized, Chocolate, Citric, Fermented, Herbaceous, Smoke, Immature, Woody, Apple, Honey, Burnt, Rancid, Earthy, Roasted and Whiskey). Sensory attributes were determined by a Q-certified panel (six men and three women with an age range between 25-49 years) and using the Specialty Coffee Association of America (2009) coffee flavor wheel. Subsequently, both panels indicated the memories generated by the coffee samples using the vocabulary generated in Phase 1 and the emotions that they evoked according to the EsSense25 emotion vocabulary (Nestrud et al., 2016). For the collection of data on attributes, memories, and emotions, the Check-All-The-Apply (CATA) technique was used (Vidal et al., 2018). The trained panel (nine panelists) carried out a total of 11 repetitions and the consumer panel (99 people) only carried out one repetition in order to balance the number of results and make the results comparable between both panels (Mahieu et al., 2020). It should be noted that all tests (e. g., preliminary tests, analysis of attributes, memories, and emotions) were carried out by the trained panelists and consumers at home to avoid contact among people and minimize the risks of contraction by COVID-19 (Santiago-Cruz et al., 2021). To do this, local parcel services distribute samples of ground coffee for evaluation, the evaluation lists (attributes, memories and emotions), napkins, pencils, water (for cleaning the palate between samples in the case of the flavors) and a digital thermometer (Chef mode, Puebla, México) among participants. Participants informed the project leader when they received samples and materials to start their evaluation. Once the participants received the ground coffee samples, they were asked to prepare the coffee drinks at a temperature of $40 \pm 5^{\circ} \mathrm{C}$ for evaluation (Specialty Coffee Association of America, 2009). Control temperature was done during training (for the trained panel) and instructing the consumers (consumers panel) regarding the adequate cupping temperature in a preliminary session. A videoconference session using Skype ${ }^{\bullet}$ was scheduled to verify that each participant had no doubts at the time of evaluation and thus proceed to carry out the tests (Nogueira-Terrones et al., 2006). Data generated by both panels were compared in different ways in successive stages: 2) Use of memories vocabulary: this stage consisted of determining the significance of each memory using Cochran's $\mathrm{Q}$ statistical technique. The Student $\mathrm{t}$-test technique was then applied to determine possible differences in the use of positive 
and negative memories between panels. Subsequently, the confidence ellipses ( $95 \%$ and with 500 resamples) and memories map were generated using Correspondence Analysis (CA) for the comparison of memories experienced by both panels (Cadoret \& Husson, 2013; Vidal et al., 2018). 3) Correlation between sensory panels: in this stage the memories profile used by both sensory panels was correlated and 3) Correlation of the coffee memory profile with other sensory data: in this stage the memory profile of the coffees was correlated with sensory attributes and emotions per panel. For stages 2 and 3 , the Multiple Factor Analysis (MFA) and $R v$ coefficient techniques were used for data analysis (Worch et al., 2010). The Cochran's Q test, Student t-test, MFA and Rv coefficient were performed with the software XLSTAT software, version 2020 (Addinsoft, New York, NY, USA). The confidence ellipses were constructed with the package SensoMineR (Le \& Husson, 2008) implemented in the programming language $\mathrm{R}$ version 3.2.5 (R Core Team, 2019).

\section{Results and discussion}

\subsection{Phase 1: generation of memories vocabulary}

A total of 359 valid responses from consumers were used for the analysis of survey data with the WordCountAna and FAST functions from the SensoMineR package. The length of the memories words collected was between one to three words. A total of 14 and 12 of positive and negative memories $(p<0.05)$ were generated, respectively (Table 1 and 2). The positive memories Traditional Food, Party, Family, Birthplace and Childhood had the highest number of mentions ( $>80$ mentions) and negative memories with the highest number of mentions ( $>90$ mentions) were Disease, Pain, Addiction, Hurt and Stench (Tables 1 and 2).

In this phase, memories with significant values were shown according to the results of the WordCountAna and FAST functions. It was found that the positive memories such as Love

Table 1. Mention and probability values for positive memories vocabulary.

\begin{tabular}{|c|c|c|c|}
\hline Memories & Mentions & Probability & Reference \\
\hline Traditional Food & 363 & $<0.0001$ & Aiello et al.(2018) \\
\hline Party & 265 & $<0.0001$ & Alonso et al. (2004) \\
\hline Family & 229 & $<0.0001$ & Rubio-Cordoba (2014); Aiello et al. (2018); Johnson et al. (2020) \\
\hline Birthplace & 193 & $<0.0001$ & Alonso et al. (2004) \\
\hline Childhood & 88 & $<0.0001$ & Alonso et al. (2004); Navarro Bravo et al. (2008) \\
\hline Friendship & 55 & $<0.0001$ & Ricarte et al. (2013); Rubio-Cordoba (2014) \\
\hline Sport & 45 & $<0.0001$ & Cho et al. (2019) \\
\hline Couple & 31 & $<0.0001$ & Alonso et al. (2004) \\
\hline aTime of the year & 31 & $<0.0001$ & Alonso et al. (2004) \\
\hline${ }^{\mathrm{b}}$ Climate & 12 & $<0.0001$ & Alonso et al. (2004) \\
\hline Alive & 7 & 0.04 & Alonso et al. (2004); Johnson et al. (2020) \\
\hline Gift & 3 & 0.002 & Alonso et al. (2004) \\
\hline Love & 10 & 0.08 & Alonso et al. (2004); Johnson et al. (2020) \\
\hline Nature & 5 & 0.45 & Alonso et al. (2004); Johnson et al. (2020) \\
\hline
\end{tabular}

The probability values were obtained with the WordCountAna and FAST algorithms (Cadoret et al., 2009; Kostov et al., 2014). a,b For the positive memories, time of year and climate were defragmented according to the seasons (Spring, Summer, Fall, Winter) and climates (Rainy weather, Cold weather, Hot weather, Mild weather).

Table 2. Mention and probability values for negative memories vocabulary.

\begin{tabular}{lccc}
\hline \multicolumn{1}{c}{ Memories } & Mentions & Probability & Reference \\
\hline Disease & 686 & $<0.0001$ & $<0.0001$ \\
Pain & 221 & $<0.0001$ & Alonso et al. (2004); Ricarte et al. (2013) \\
Addiction & 140 & $<0.0001$ & Alonso et al. (2004); Ricarte et al. (2013) \\
Hurt & 117 & Yamada et al. (2014) \\
Stench & 92 & $<0.0001$ & Alonso et al. (2004); Ricarte et al. (2013) \\
Death & 41 & $<0.0001$ & Jiménez (2014) \\
Interpersonal conflict & 22 & $<0.0001$ & Alonso et al. (2004); Manzanero et al. (2015); Johnson et al. (2020) \\
Poverty & 61 & $<0.0001$ & Manzanero et al. (2015); Johnson et al. (2020) \\
Accident & 22 & Alonso et al. (2004); Johnson et al. (2020) \\
Obesity & 94 & 0.0001 & Zeng et al. (2020) \\
Excesses & 81 & 0.78 & Alonso et al. (2004); Rubio-Cordoba (2014); Manzanero et al. (2015) \\
Blood & 3 & 0.244 & Moreno-Padilla et al. (2018); Blau et al. (2020) \\
\hline
\end{tabular}

The probability values were obtained with the WordCountAna and FAST algorithms (Cadoret et al., 2009; Kostov et al., 2014). 
and Nature and the negative memories Obesity and Excesses were not significant $(p>0.05)$; however, they were considered on the list of memories because they were cited by at least three consumers (Perrin et al., 2008; Kostov et al., 2014). The positive and negative memories found in this research have also been detected in various studies related to false memories and false recognition production indexes (Alonso et al., 2004), design of the Autobiographical Memories Test operation (Ricarte et al., 2013), analysis of aromas in artisan accessories stores (RubioCordoba, 2014), positive and negative memories generated in the context of war (Manzanero et al., 2015), analysis of episodic memories versus natural and processed foods (Aiello et al., 2018), nostalgia for sports tourists in the decision-making process (Cho et al., 2019) and concerns and reflections on the COVID-19 pandemic (Johnson et al., 2020). It is worth mentioning that no research was found that included the use of the word Obesity as a memories; However, its use is justified because the usefulness of memories depends not only on current consumption, but also on the usefulness of memory derived from past consumption (Zeng et al., 2020). In the same sense, Excess negative memory could have been mentioned by consumers because it is related to hypersensitivity to food stimuli that influence the formation of people's preferences, for example, consumers that have a tendency for the consumption of foods rich in fat or fast foods (Moreno-Padilla et al., 2018; Blau et al., 2020). The word Addiction could be mentioned by consumers due to the dependence on products of alcoholic beverages, cola drinks, coffee, among others (Yamada et al., 2014; Bhumiratana et al., 2019). Finally, the negative memories, Stench or unpleasant odors is also of importance according to
Jiménez (2014) who mentioned that this smell can influence acceptance or rejection of interpersonal relationships and is linked to feelings, sensations, or images such as food (e.g., cheese, fermented food, egg, among others), aspects of personal hygiene, state of conservation of objects or places (e.g., shoes, clothing, closed premises, among others).

\subsection{Phase 2: application of the vocabulary of memories in coffees}

\section{Use of memories vocabulary}

The results on the use of memories vocabulary and their respective probability values are shown in Table 3 and 4 . The trained panel responded with positive memories: Childhood, Couple, Fall, Hot weather, Love and Nature; These positive memories had Cochran's Q test probability values higher than 0.05 . The trained panel minimally used negative memories: Addiction, Interpersonal conflict, Obesity, Excesses and Blood, which were not significant $(p>0.05)$. The trained panel responded with 65 and $53 \%$ of positive and negative memories, respectively. Table 4 shows the results from the consumer panel indicating that positive memories Family, Childhood, Friendship, Cold weather and Mild weather and negative memories Disease, Pain, Stench and Death were significant. The consumer panel responded with only five and four positive and negative memories, respectively for characterizing the coffee samples. This represents 25 and $36.36 \%$ of positive and negative memories. The results of the Student $\mathrm{t}$-test showed that there were no significant differences in the

Table 3. Number of positive and negative memories mentioned in coffee samples with their respective probability values of the Cochran's Q test of the trained panel.

\begin{tabular}{|c|c|c|c|c|c|}
\hline Positive memories & Mentions & $p$ values & Negative memories & Mentions & $p$ values \\
\hline Traditional Food & 107 & $<0.0001$ & Disease & 87 & $<0.0001$ \\
\hline Party & 147 & ns & Pain & 103 & $<0.0001$ \\
\hline Family & 174 & $<0.0001$ & Addiction & 5 & ns \\
\hline Childhood & 13 & ns & Stench & 40 & $<0.0001$ \\
\hline Friendship & 92 & $<0.0001$ & Death & 59 & $<0.0001$ \\
\hline Spring & 92 & $<0.0001$ & Accident & 11 & 0.001 \\
\hline Summer & 88 & $<0.0001$ & Obesity & 0 & ns \\
\hline Fall & 146 & ns & Excesses & 0 & ns \\
\hline Winter & 329 & 0.004 & Blood & 0 & ns \\
\hline Rainy weather & 243 & 0.021 & & & \\
\hline Gift & 63 & $<0.0001$ & & & \\
\hline Love & 0 & ns & & & \\
\hline Nature & 0 & ns & & & \\
\hline
\end{tabular}

ns: is not significant. The data resulted from 11 repetitions carried out by the trained panel. 
Table 4. Number of positive and negative memories mentioned in coffee samples with their respective probability values of the Cochran's Q test of the consumer panel.

\begin{tabular}{|c|c|c|c|c|c|}
\hline Positive memories & Mentions & $p$ values & Negative memories & Mentions & $p$ values \\
\hline Traditional Food & 66 & ns & Disease & 67 & 0.018 \\
\hline Party & 71 & ns & Pain & 80 & $<0.0001$ \\
\hline Family & 129 & 0.038 & Addiction & 24 & ns \\
\hline Birthplace & 117 & ns & Hurt & 45 & ns \\
\hline Childhood & 45 & 0.029 & Stench & 15 & 0.013 \\
\hline Friendship & 79 & 0.049 & Death & 62 & 0.007 \\
\hline Spring & 75 & ns & Accident & 22 & ns \\
\hline Summer & 70 & ns & Obesity & 8 & ns \\
\hline Fall & 128 & ns & Excesses & 0 & ns \\
\hline Winter & 177 & ns & Blood & 0 & ns \\
\hline Rainy weather & 119 & ns & & & \\
\hline Alive & 60 & ns & & & \\
\hline Gift & 38 & ns & & & \\
\hline Love & 0 & ns & & & \\
\hline Nature & 0 & ns & & & \\
\hline
\end{tabular}

ns: is not significant. Data resulted from one repetition conducted by the consumer panel.

use of positive $\left(t_{\text {positives }}=2.25, \mathrm{p}=0.26\right)$ and negatives memories $\left(t_{\text {negatives }}=3.66, \mathrm{p}=0.17\right)$ between the panels used in this study.

In Figure 1, confidence ellipses and memories maps generated with the data from the trained panel and the consumer panel are shown. Figures $1 \mathrm{~A}$ and $\mathrm{C}$ show that the trained panel and the consumer panel correctly discriminate $(p<0.05)$ artisan coffees (AC1, AC2 and AC3) from industrial coffees (IC1, IC2 and IC3) according to the resulting memories profile. Figure $1 \mathrm{~B}$ and $\mathrm{D}$ show the memories map of coffees generated by both, trained panel and consumer panel. It was found that the trained panel (Figure 1B), when evaluating the samples of artisanal coffees, experienced positive memories Traditional Food, Friendship, Mild weather, Birthplace, Spring, Alive, Gift and Summer while the consumer panel experienced the positive memories Family, Friendship, Mild weather and Rainy weather for the same artisan coffee samples (Figure 1D). In the same way, the negative memories evoked by the artisan coffees in the trained panel was Accident (Figure 1B) and in the case of the consumer panel it was Disease (Figure 1D). In the case of industrialized coffees, the trained panel experienced the positive memories Rainy weather, Cold weather, Winter and Sport (Figure 1B) while the consumer panel associated positive memories Rainy weather, Cold weather and Childhood (Figure 1D). In the case of negative memories, the trained panel associated the memories Hurt, Pain, Stench, Death, Poverty and Disease (Figure 1B) while the consumer panel used the following negative memories Death, Stench and Pain (Figure 1D). Discrimination of artisanal vs. industrial coffee samples using confidence ellipses, memories maps per panel and the same direction of positive memories (Friendship, Family, Cold weather and Mild weather), and the negative memories
(Death, Stench and Pain) in the factorial plane together with the high values of the $R v$ coefficient, indicated that the vocabulary of memories can be used in the context of trained judges and consumers as results were similar. This result is supported by Worch al. (2010), who showed that trained judges and consumers discriminate in a similar way. From the point of view of the use of the profile of memories in conjunction with the sensory attributes and emotions, high values of association were found between different profiles used in both panels. Artisan coffees evoked different positive memories (Traditional food, Friendship, Mild weather, Birthplace, Spring, Gift, Alive and Summer) and were associated with different sensory attributes typical of coffee with desirable characteristics (e. g, Cinnamon-F, Cinnamon-A, Caramel-A, Chocolate-A, Chocolate-F, Fruity-F, Caramelized-F, Sweet-A, Sweet-T, Honey-F and Nut-A) and generated the positive emotions found in this research.

\section{Correlation between sensory panels}

The correlation between sensory panels using MFA is shown in Figure 2 where a high proximity is observed between both groups (Figure 2A). This was confirmed by the partial clouds (Figure 2B) where the proximity of both sensory panels to the midpoint represented by each coffee sample was observed. The aforementioned proximity was verified by a correlation value $R v_{\text {trained-consumers }}=0.92(p \leq 0.05)$. This result could be due to the positive memories Family, Friendship, Cold weather, Mild weather as well as negative memories Death, Stench and Pain which showed similar direction in the factorial plane (Figure 2C), indicating that both panels used these memories in a similar way for the evaluation of coffee samples. 

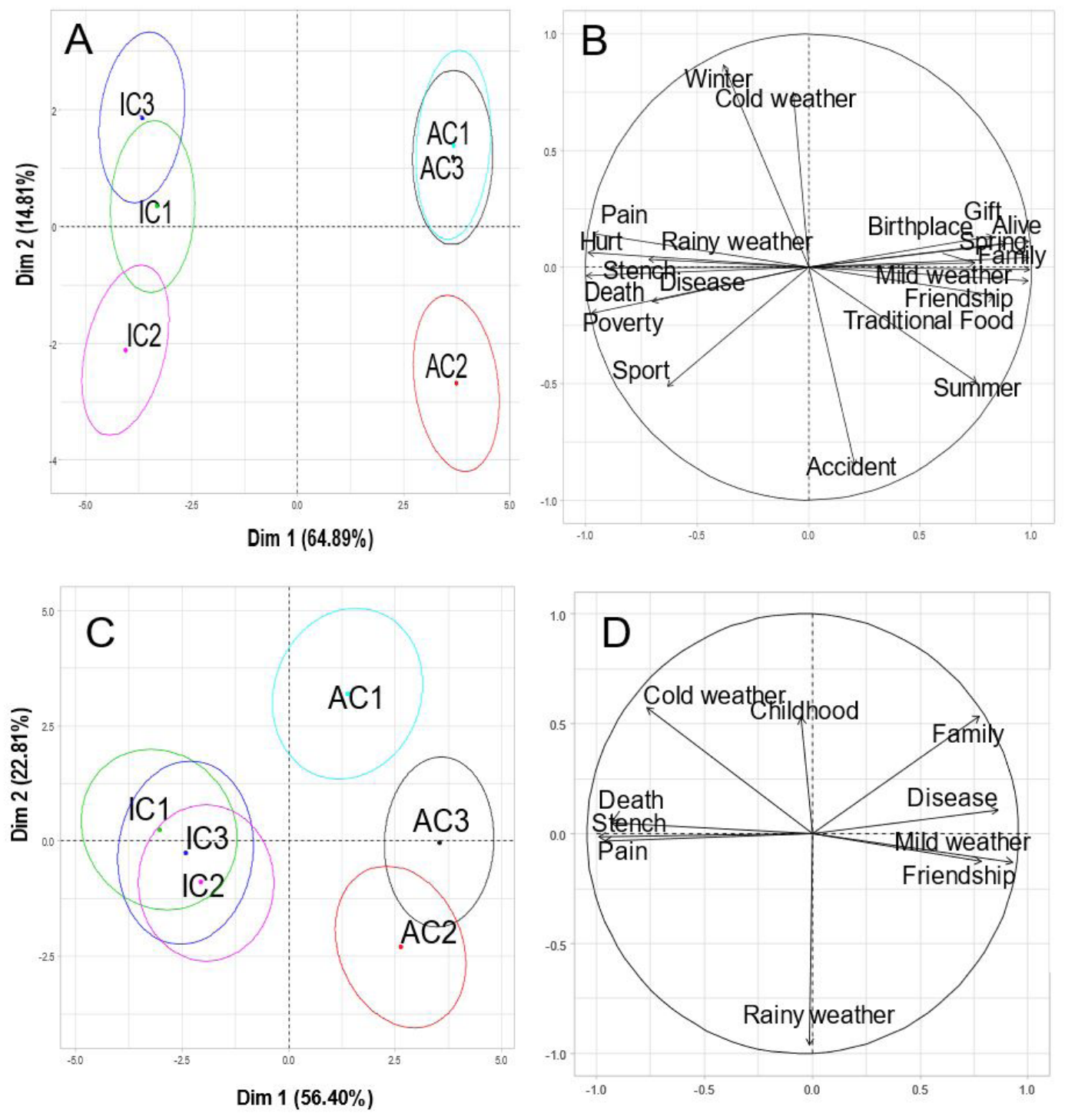

Figure 1. (A and B) Memories map and confidence ellipses with data from the trained panel; (C and D) Map of memories and confidence ellipses with data from the consumer panel. The maps were generated with the memories that had probabilities $\leq 0.05$ of the Cochran's $\mathrm{Q}$ test. AC $=$ Artisan coffee; IC = Industrial coffee.

Correlation of the coffee memories profile with other sensory data

Figure 3 shows the results of MFA for the correlation of the memories profile of coffees for each type of panel. Figures $3 \mathrm{~A}$ and $\mathrm{B}$ show that the memories profile is strongly correlated with the profiles of sensory attributes and emotions for each type of panel. For example, the trained panel obtained values of $R v_{\text {memories-attributes }}=0.95, R v_{\text {memories-emotions }}=0.94$ whereas the consumer panel obtained values of $R v_{\text {memories-attributes }}=0.84$, $R v_{\text {memories-emotions }}=0.76$. These values indicate that memories vocabulary can complement data on sensory attributes and emotions from a trained panel or a consumer panel. For example, according to results from both panels used in this research, the same discrimination was observed between artisanal and industrial coffee samples using the data from memories, emotions, and sensory attributes. (Figure $3 \mathrm{C}$ and D). After evaluating artisanal coffees, the trained panel experienced positive memories Traditional Food, Friendship, Mild weather, Birthplace, Spring, Alive, Gift and Summer as well as the negative memories Accident which could be generated by different sensory attributes Acidic- T, Cinnamon-F, Citric- $F$, Cinnamon-A, Caramel-A, Chocolate-A, Chocolate-F, Fruity- $F$, Caramelized-F, Sweet-A, Sweet-T, Honey-F and Walnut-A and that immediately evoked the emotions Adventurous, Active, Good nature, Good, Calm, Happy, Enthusiastic, Free, Joyful, Secure, and Satisfies (Figure 3C) Similarly, consumers experienced positive memories Family, Friendship, Mild weather and Childhood and the negative memories Disease could be generated by sensory attributes Acidic-T, Fruity-F, Caramel-A, Caramelized-F, Citrus-F, Sweet-T, Sweet-A, Apple-F, Honey-F and Nut-F and then they experienced the emotion Pleasant. For industrial coffees, the trained panel experienced different 

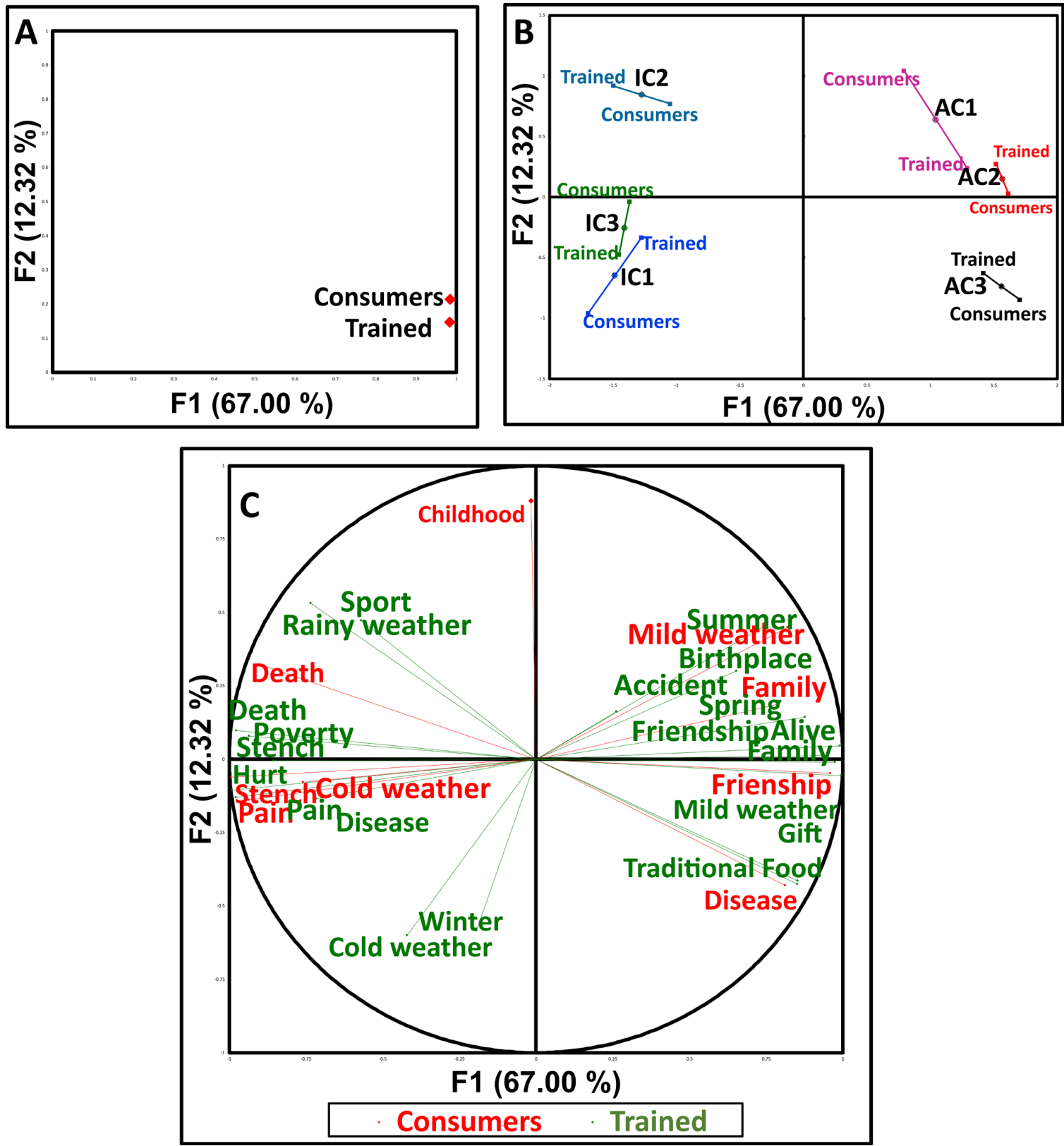

Figure 2. Multiple Factorial Analysis. (A) Representation of the panels; (B) Partial clouds; and (C) Memories used by the trained panel and the consumer panel. The maps were generated with the memories that had probabilities $<0.05$ of the Cochran's $\mathrm{Q}$ test. $\mathrm{AC}=\mathrm{Artisan}$ coffee; IC $=$ Industrial coffee.

positive memories (Rainy weather, Cold weather, Winter and Sport) and different negative memories (Hurt, Pain, Stench, Death, Poverty and Disease) that could be generated by the sensory attributes Bitter Chocolate-F, Coffee peel-A, Fermented-F, Smoke-F, Wood-A, Wood-F, Burnt-A, Burnt-F, Rancid-F, Earthy-A, and Spicy-A and that later generated emotions Bored, Aggressive, Disgusted, Nostalgic, Worried, and Wild (Figure 3C). In this same sense, the consumer panel, after consuming the industrialized coffees, generated the positive memories Cold weather and negative memories Pain, Stench and Death that could be associated with the sensory attributes Bitter-T, Chocolate-F, Smoke-F, Wood-A, Wood-F, Burnt-A, Burnt-F, Earth-F and Earthy-A and that contributed to generate the emotions Aggressive, Guilty, Disgusted and Wild according to the proximity shown in Figure. 3D. In the case of negative memories Accident and Disease they may be mentioned because in Mexico, coffee is commonly served in sad situations such as funerals. On the other hand, the positive memories that industrialized coffees evoke were oriented toward the type of climate and sport. This result may be associated with the fact that people consider this type of coffees to be mostly consumed in places with cold and rainy climates while the Sports memories could be associated with people who use coffee as an energy drink (Tamamoto et al., 2010). Negative memories of industrialized coffees can be associated with the effect of seasonality on consumers. In 

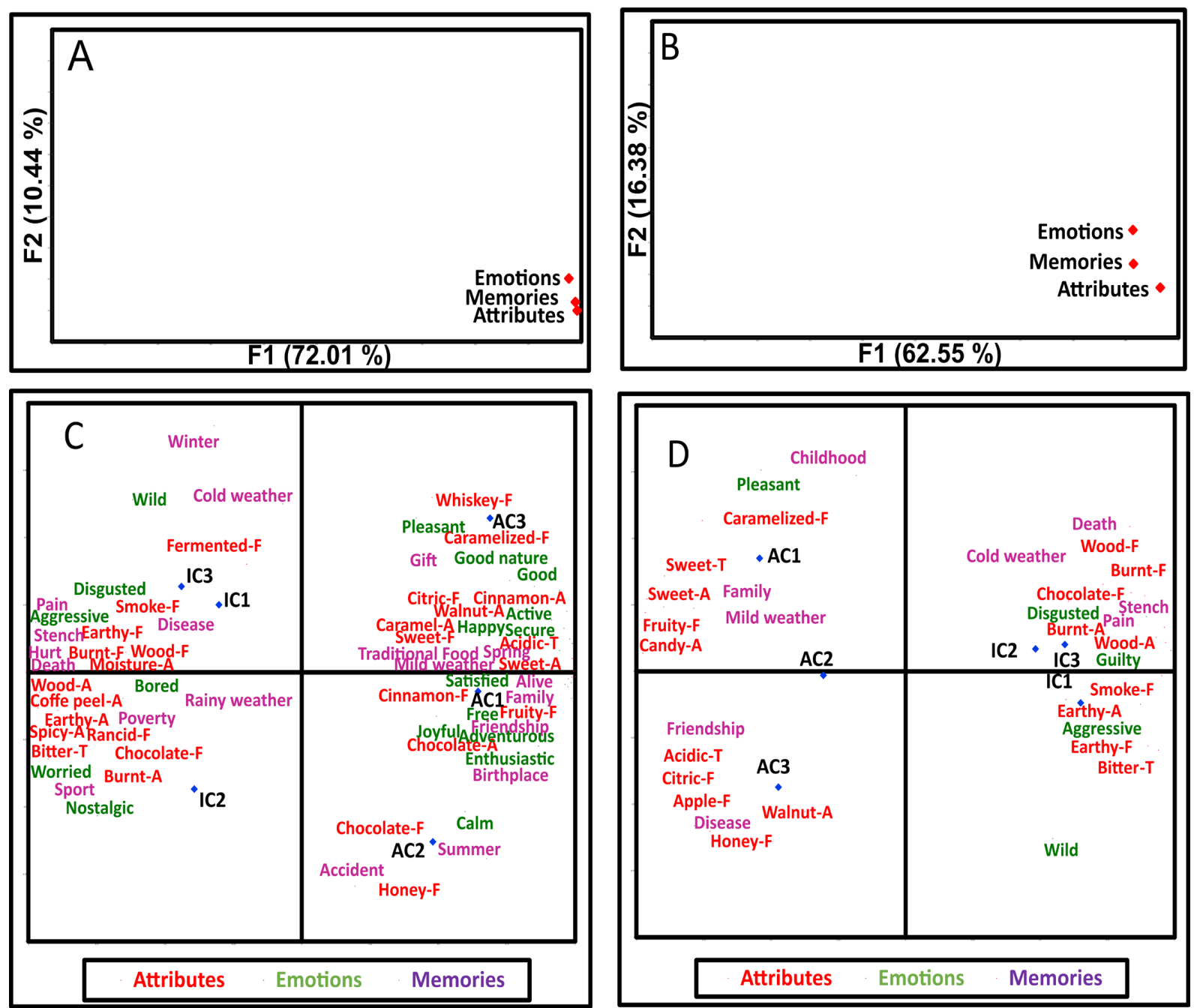

Figure 3. Multiple Factorial Analysis. (A) Representation of attributes, memories and emotions for the trained panel; (B) Representation of attributes, memories and emotions for the consumer panel; (C) Sensory characterization of coffees carried out by the trained panel; (D) Sensory characterization of coffees carried out by the consumer panel. The sensory maps were generated with the memories, sensory attributes and emotions that had probabilities $<0.05$ of the Cochran's $\mathrm{Q}$ test. $\mathrm{AC}=$ Artisan coffee; $\mathrm{IC}=$ Industrial coffee; $\mathrm{A}=\mathrm{Aroma}$; $=$ Flavor; $\mathrm{T}=$ Taste.

this sense, there is scientific evidence that indicates that the time of year has an important effect on people and that it can generate different behavioral changes such as anxiety, depression, irritability, which have also been associated with a low economic level (Øyane et al., 2010). This justifies the negative memories Poverty. Negative memories Hurt, Pain, Poverty and Disease can be derived from the previous behavioral changes. Additionally, the negative memories Death could be cognitively associated with celebrations such as the "Day of the Dead" in Mexico (Brandes, 1998), where coffee is commonly consumed to accompany other foods, as well as at the funerals of a family member or friend. Positive and negative memories of industrialized coffees could have been evoked by different sensory attributes considered as negative such as spicy, rancidity, wood and earthy that after the mentioned memories evoked negative emotions (e.g., Bored, Aggressive, Guilty, Disgusted, Nostalgic, Worried and Wild). Both, emotions, and sensory attributes mentioned above were also reported in the studies of Bhumiratana et al. (2019) and Ramírez-Rivera et al. (2021) who evaluated coffee samples. Results from this study suggest that this first approximation of the memories vocabulary can be further evaluated with more emphasis in different situations such as 1) relationship of memories with preference data to explore in depth the possible memories that have the greatest influence on the purchase intent; 2 ) intra and inter-cultural studies to verify if the vocabulary of memories of this research is understood and used in the same way between different cultures; 3 ) to verify how the memories generated by the consumption of food at different times of the year can vary, since it has been shown that seasonality influences people's attitudes; 4 ) analysis of the duration of memories during consumption in real time using dynamic sensory techniques such as Temporal Dominance of Sensations; 5) the application of this memories vocabulary in other products where sensory evaluation has been used, such as cosmetics, medicines, automobiles, among others. 
Likewise, this list of memories can be expanded or reduced according to the interests of the industry and researchers in the sensory field.

\section{Conclusions}

The proposed memories vocabulary has been generated from the sensory field and its validity and reliability is supported by the applied statistical treatment and the comparison with the memories terms published in the area of psychology. The memories vocabulary consisted of a total of 14 and 12 positive and negative memories terms, respectively. This number of memories were the most statistically representative based on the number of mentions and probabilities according to the textural analysis techniques (Factorial Approach for Sorting Task and Word-Count Based Methods Analysis). The memories vocabulary was used in a similar way by trained judges and consumers. The high correlations between sensory attributes (0.84-0.95) and emotions (0.76-0.94) with the memories (obtained using the memories vocabulary) indicated that the use of this vocabulary in conjunction with sensory attributes and emotions is a significant complement for the generation of a more robust food product characterization to achieve an improved connection between sensory science and marketing.

\section{References}

Aiello, M., Vignando, M., Foroni, F., Pergola, G., Rossi, P., Silveri, M. C., \& Rumiati, R. I. (2018). Episodic memory for natural and transformed food. Cortex, 107, 13-20. http://dx.doi.org/10.1016/j. cortex.2018.04.013. PMid:29843896.

Alonso, M. Á., Fernández, Á., Díez, E., \& Beato, M. S. (2004). Índices de producción de falso recuerdo y falso reconocimiento para 55 listas de palabras en castellano. Psicothema, 16(3), 357-362. Retrieved from https://www.redalyc.org/pdf/727/72716303.pdf

Baima, J. S., \& Ribotta, P. D. (2019). El análisis de imágenes como herramienta de monitoreo en la deshidratación de rodajas de banana. Brazilian Journal of Food Technology, 22, e2018231. http://dx.doi. org/10.1590/1981-6723.23118.

Bettman, J. R. (1979). Memory factors in consumer choice: a review. Journal of Marketing, 43(2), 37-53. http://dx.doi.org/10.1177/002224297904300205.

Bhumiratana, N., Wolf, M., Chambers, I. V. E. 4th, \& Adhikari, K. (2019). Coffee drinking and emotions: Are There key sensory drivers for emotions? Beverages, 5(2), 27. http://dx.doi.org/10.3390/ beverages 5020027.

Blancher, G., Clavier, B., Egoroff, C., Duineveld, K., \& Parcon, J. (2012). A method to investigate the stability of a sorting map. Food Quality and Preference, 23(1), 36-43. http://dx.doi.org/10.1016/j. foodqual.2011.06.010. PMid:23175601.

Blau, L. E., Orloff, N., \& Hormes, J. M. (2020). The transdiagnostic nature of cravings: smoking cessation and food craving in pregnancy. Midwifery, 87, 102730. http://dx.doi.org/10.1016/j.midw.2020.102730. PMid:32434103.

Brandes, S. (1998). The day of the dead, Halloween, and the Quest for Mexican National Identity. Journal of American Folklore, 111(442), 359-380. http://dx.doi.org/10.2307/541045.

Braun-Endo, A. C., \& Brás-Roque, M. C. (2017). Attention, memory and perception: a conceptual analysis of Neuropsychology applied to advertising and its influence on consumer behavior. Intercom -
Revista Brasileira de Ciências da Comunicação, 40(1), 77-95. http:// dx.doi.org/10.1590/1809-5844201715.

Broche-Pérez, Y., Herrera-Jiménez, L. F., \& Omar-Martínez, E. (2016). Bases neurales de la toma de decisiones. Neurologia (Barcelona, Spain), 31(5), 319-325. http://dx.doi.org/10.1016/j.nrl.2015.03.001. PMid:25976946.

Cadoret, M., \& Husson, F. (2013). Construction and evaluation of confidence ellipses applied at sensory data. Food Quality and Preference, 28(1), 106-115. http://dx.doi.org/10.1016/j.foodqual.2012.09.005.

Cadoret, M., Lê, S., \& Pagès, J. (2009). A Factorial Approach for Sorting Task Data (FAST). Food Quality and Preference, 20(6), 410-417. http://dx.doi.org/10.1016/j.foodqual.2009.02.010.

Cho, H., Joo, D., Moore, D. W., \& Norman, W. C. (2019). Sport tourists' nostalgia and its effect on attitude and intentions: a multilevel approach. Tourism Management Perspectives, 32, 100563. http:// dx.doi.org/10.1016/j.tmp.2019.100563.

Favalli, S., Skov, T., \& Byrne, D. V. (2013). Sensory perception and understanding of food uniqueness: From the traditional to the novel. Food Research International, 50(1), 176-188. http://dx.doi. org/10.1016/j.foodres.2012.10.007.

Gierczynski, I., Guichard, E., \& Laboure, H. (2011). Aroma perception in dairy products: the roles of texture, aroma release and consumer physiology. A review. Flavour and Fragrance Journal, 26(3), 141-152. http://dx.doi.org/10.1002/ffj.2036.

Herz, M., \& Brunk, K. H. (2017). Conceptual Advances in Consumers' Semantic and Episodic Brand Memories: A Mixed Methods Exploration. Psychology and Marketing, 34(1), 70-91. http://dx.doi. org/10.1002/mar.20974.

Howe, D., Anderson, R. J., \& Dewhurst, S. A. (2017). False memories, but not false beliefs, affect implicit attitudes for food preferences. Acta Psychologica, 179, 14-22. http://dx.doi.org/10.1016/j.actpsy.2017.07.002. PMid:28697479.

International Organization for Standardization - ISO. (1993). ISO 85861: sensory analysis: general guidance for the selection, training, and monitoring of assessors, part 1: selected assessors. Switzerland: ISO.

International Organization for Standardization - ISO. (1994). ISO 11035: sensory analysis: identification and selection of descriptors for establishing a sensory profile by a multidimensional approach. Switzerland: ISO.

International Organization for Standardization - ISO. (2004a). ISO 10399: sensory analysis: methodology: duo-trio test. Switzerland: ISO.

International Organization for Standardization - ISO. (2004b). ISO 16820: sensory analysis: methodology: sequential analysis. Switzerland: ISO.

International Organization for Standardization - ISO. (2004c). ISO 4120: sensory analysis: methodology: sequential analysis. Switzerland: ISO.

International Organization for Standardization - ISO. (2005). ISO 5496 : sensory analysis: methodology: initiation and training of assessors in the detection and recognition of odours. Switzerland: ISO.

International Organization for Standardization - ISO. (2008). ISO 6668: green coffee: preparation of samples for use in sensory analysis. Switzerland: ISO.

Jiang, Y., King, J. M., \& Prinyawiwatkul, W. (2014). A review of measurement and relationships between food, eating behavior and emotion. Trends in Food Science \& Technology, 36(1), 15-28. http:// dx.doi.org/10.1016/j.tifs.2013.12.005.

Jiménez, A. M. E. (2014). Olores agradables y desagradables en las exposiciones científicas orales. Medisan, 18(4), 593-599.

Johnson, M. C., Saletti-Cuesta, L., \& Tumas, N. (2020). Emociones, preocupaciones y reflexiones frente a la pandemia del COVID-19 
en Argentina. Ciência \& Saúde Coletiva, 25(1, Suppl. 1), 24472456. http://dx.doi.org/10.1590/1413-81232020256.1.10472020. PMid:32520288.

Jose-Coutinho, A., Avila, P., \& Ricardo-Da-Silva, J. M. (2015). Sensory profile of portuguese white wines using long-term memory: a novel nationwide approach. Journal of Sensory Studies, 30(5), 381-394. http://dx.doi.org/10.1111/joss.12165.

King, S. C., \& Meiselman, H. L. (2010). Development of a method to measure consumer emotions associated with foods. Food Quality and Preference, 21(2), 168-177. http://dx.doi.org/10.1016/j. foodqual.2009.02.005.

Köster, E. P. (2003). The psychology of food choice: Some often encountered fallacies. Food Quality and Preference, 14(5-6), 359-373. http://dx.doi.org/10.1016/S0950-3293(03)00017-X.

Kostov, B., Bécue-Bertaut, M., \& Husson, F. (2014). An original methodology for the analysis and interpretation of word-count based methods: multiple factor analysis for contingency tables complemented by consensual words. Food Quality and Preference, 32, 35-40. http://dx.doi.org/10.1016/j.foodqual.2013.06.009.

Laguna, L., Fiszman, S., Puerta, P., Chaya, C., \& Tárrega, A. (2020). The impact of COVID-19 lockdown on food priorities: results from a preliminary study using social media and an online survey with Spanish consumers. Food Quality and Preference, 86, 104028. http://dx.doi.org/10.1016/j.foodqual.2020.104028. PMid:32834551.

Le, S., \& Husson, F. (2008). Sensominer: A package for sensory data analysis. Journal of Sensory Studies, 23(1), 14-25. http://dx.doi. org/10.1111/j.1745-459X.2007.00137.x.

Lin, L., \& Mao, P. C. (2015). Food for memories and culture: a content analysis study of food specialties and souvenirs. Journal of Hospitality and Tourism Management, 22, 19-29. http://dx.doi.org/10.1016/j. jhtm.2014.12.001.

Mahieu, B., Visalli, M., Thomas, A., \& Schlich, P. (2020). Free-comment outperformed Check-All-That-Apply in the sensory characterisation of wines with consumers at home. Food Quality and Preference, 84, 103937. http://dx.doi.org/10.1016/j.foodqual.2020.103937.

Mahieu, B., Visalli, M., Thomas, A., \& Schlich, P. (2021). An investigation of the stability of Free-Comment and Check-All-That-Apply in two consumer studies on red wines and milk chocolates. Food Quality and Preference, 90, 104159. http://dx.doi.org/10.1016/j. foodqual.2020.104159.

Manzanero, A. L., López, B., Aróztegui, J., \& El-Astal, S. (2015). Autobiographical memories for negative and positive events in war contexts. Anuário de Psicología Jurídica, 25(1), 57-64. http://dx.doi. org/10.1016/j.apj.2015.02.001.

Mark, J., Williams, G., \& Dritschel, B. H. (1992). Categoric and extended autobiographical memories. In M. A. Conway, D. C. Rubin, H. Spinnler \& W. A. Wagenaar (Eds.), Theoretical perspectives on autobiographical memory (pp. 391-410). (NATO ASI Series D: Behavioural and Social Sciences, No. 65). Dordrecht: Springer. http://dx.doi.org/10.1007/978-94-015-7967-4_23.

McKenzie, K., Metcalf, D. A., \& Saliba, A. (2021). Validation of the food technology neophobia scale in a Chinese sample using exploratory and confirmatory factor analysis. Food Quality and Preference, 89(8), 104148. http://dx.doi.org/10.1016/j.foodqual.2020.104148.

Mojet, J., \& Köster, E. P. (2005). Sensory memory and food texture. Food Quality and Preference, 16(3), 251-266. http://dx.doi.org/10.1016/j. foodqual.2004.04.017.

Moreno-Padilla, M., Verdejo-Román, J., Fernández-Serrano, M. J., Reyes del Paso, G. A., \& Verdejo-García, A. (2018). Increased food choice-evoked brain activation in adolescents with excess weight:
Relationship with subjective craving and behavior. Appetite, 131, 7-13. http://dx.doi.org/10.1016/j.appet.2018.08.031. PMid:30165099.

Morin-Audebrand, L., Laureati, M., Sulmont-Rossé, C., Issanchou, S., Köster, E. P., \& Mojet, J. (2009). Different sensory aspects of a food are not remembered with equal acuity. Food Quality and Preference, 20(2), 92-99. http://dx.doi.org/10.1016/j.foodqual.2007.09.003.

Navarro Bravo, B., Latorre Postigo, J. M., López-Torres Hidalgo, J., \& Andrés Pretel, F. (2008). Memoria autobiográfica y entrenamiento en revisión de vida como método de mejora del estado de ánimo en la vejez. Revista Clinica Media Familiar, 2(4), 171-177. http:// dx.doi.org/10.4321/S1699-695X2008000200007.

Nestrud, M. A., Meiselman, H. L., King, S. C., Lesher, L. L., \& Cardello, A. V. (2016). Development of EsSense25, a shorter version of the EsSense Profile ${ }^{\circledR}$. Food Quality and Preference, 48, 107-117. http:// dx.doi.org/10.1016/j.foodqual.2015.08.005.

Nogueira-Terrones, H., Tinet, C., Curt, C., Trystram, G., \& Hossenlopp, J. (2006). Using the internet for descriptive sensory analysis: Formation, training and follow-up of a taste-test panel over the web. Journal of Sensory Studies, 21(2), 180-202. http://dx.doi.org/10.1111/j.1745459X.2006.00060.x.

Oliveira e Silva, R., Carmo Rouxinol, M. I. F., \& Patarata, L. A. S. C. (2020). The use of photography to perform an online consumer test on the freshness of chicken breast and the extensión of shelf life. Journal of Sensory Studies, 35(3), e12565. http://dx.doi.org/10.1111/ joss. 12565.

Øyane, N. M., Ursin, R., Pallesen, S., Holsten, F., \& Bjorvatn, B. (2010). Increased health risk in subjects with high self-reported seasonality. PLoS One, 5(3), e9498. http://dx.doi.org/10.1371/journal.pone.0009498. PMid:20209129.

Paixão, J. A., Tavares, E., Fo., \& Bolini, H. M. A. (2020). Investigation of alcohol factor influence in quantitative descriptive analysis and in the time-intensity profile of alcoholic and non-alcoholic Commercial Pilsen Beers Samples. Beverages, 6(4), 73. http://dx.doi.org/10.3390/ beverages6040073.

Perrin, L., Symoneaux, R., Maître, I., Asselin, C., Jourjon, F., \& Pagès, J. (2008). Comparison of three sensory methods for use with the Napping ${ }^{\oplus}$ procedure: Case of ten wines from Loire valley. Food Quality and Preference, 19(1), 1-11. http://dx.doi.org/10.1016/j. foodqual.2007.06.005.

R Core Team. (2019). R: a language and environment for statistical computing. Vienna: R Foundation for Statistical Computing. Retrieved from https://www.R-project.org/

Ramírez-Rivera, E. J., Díaz-Rivera, P., Ramón-Canul, L. G., Juárez-Barrientos, J. M., Rodríguez-Miranda, J., Herman-Lara, E., Prinyawiwatkul, W., \& Herrera-Corredor, J. A. (2021). Technique for order preference by similarity to ideal solution (TOPSIS) method for the generation of external preference mapping with rapid sensometric techniques. Journal of the Science of Food and Agriculture, 101(8), 3298-3307. http://dx.doi.org/10.1002/jsfa.10959. PMid:33222200.

Ramírez-Rivera, E. J., Díaz-Rivera, P., Ramón-Canul, L. G., JuárezBarrientos, J. M., Rodríguez-Miranda, J., Herman-Lara, E., \& Herrera-Corredor, J. A. (2018). Comparison of performance and quantitative descriptive analysis sensory profiling and its relationship to consumer liking between the artisanal cheese producers' panel and the descriptive trained panel. Journal of Dairy Science, 101(7), 5851-5864. http://dx.doi.org/10.3168/jds.2017-14213. PMid:29705419.

Ricarte, T. J. J., Latorre, P. J. M., \& Ros, S. L. (2013). Diseño y análisis del funcionamiento del test de memoria autobiográfica en población española. Apuntes de Psicología, 31(1), 3-10. Retrieved from http:// www.apuntesdepsicologia.es/index.php/revista/article/view/292 
Rubio-Cordoba, M. M. (2014). Aromas con sentido: análisis del impacto de una estrategia de marketing olfativo aplicada a los consumidores de una tienda de accesorios artesanales (Tesis de licenciatura). Santiago de Cali: Universidad Autónoma de Occidente. Retrieved from http:// red.uao.edu.co/handle/10614/5800

Santiago-Cruz, I. A., Jesús Ramírez-Rivera, E., López-Espíndola, M., Hidalgo-Contreras, J. V., Prinyawiwatkul, W., \& Herrera-Corredor, J. A. (2021). Use of online questionnaires to identify emotions elicited by different types of corn tortilla in consumers of different gender and age. Journal of Sensory Studies, 36(2), e12638. http://dx.doi. org/10.1111/joss.12638.

Sester, C., Dacremont, C., Deroy, O., \& Valentin, D. (2013). Investigating consumer's representations of beers through a free association task: a comparison between packaging and blind conditions. Food Quality and Preference, 28(2), 475-483. http://dx.doi.org/10.1016/j. foodqual.2012.11.005.

Shaw, S. D., \& Bagozzi, R. P. (2018). The neuropsychology of consumer behavior and marketing. Counselling Psychology Review, 1(1), 22-40. http://dx.doi.org/10.1002/arcp.1006.

Specialty Coffee Association of America - SCAA. (2009). Protocols: cupping specialty coffee. USA: SCAA.

Spinelli, S., Masi, C., Zoboli, G. P., Prescott, J., \& Monteleone, E. (2015). Emotional responses to branded and unbranded foods. Food Quality and Preference, 42, 1-11. http://dx.doi.org/10.1016/j. foodqual.2014.12.009.
Tamamoto, L. C., Schmidt, S. J., \& Lee, S. Y. (2010). Sensory profile of a model energy drink with varying levels of functional ingredients: caffeine, Ginseng, and Taurine. Journal of Food Science, 75(6), S271-S278. http://dx.doi.org/10.1111/j.1750-3841.2010.01655.x. PMid:20722948.

Vidal, L., Ares, G., Hedderley, D. I., Meyners, M., \& Jaeger, S. R. (2018). Comparison of rate-all-that-apply (RATA) and check-all-that-apply (CATA) questions across seven consumer studies. Food Quality and Preference, 67, 49-58. http://dx.doi.org/10.1016/j.foodqual.2016.12.013.

Vidal, L., Barreiro, C., Gómez, B., Ares, G., \& Giménez, A. (2013). Influence of information on consumer's evaluations using check-allthat-apply questions and sorting: A case study with milk desserts. Journal of Sensory Studies, 28(2), 125-137. http://dx.doi.org/10.1111/ joss. 12030.

Worch, T., Lê, S., \& Punter, P. (2010). How reliable are the consumers? Comparison of sensory profiles from consumers and experts. Food Quality and Preference, 21(3), 309-318. http://dx.doi.org/10.1016/j. foodqual.2009.06.001.

Yamada, A., Fukuda, H., Samejima, K., Kiyokawa, S., Ueda, K., Noba, S., \& Wanikawa, A. (2014). The effect of an analytical appreciation of colas on consumer beverage choice. Food Quality and Preference, 34, 1-4. http://dx.doi.org/10.1016/j.foodqual.2013.11.008.

Zeng, Q., Yu, X., \& Bao, T. (2020). Memory utility, food consumption and obesity. China Economic Review, 62, 101345. http://dx.doi. org/10.1016/j.chieco.2019.101345. 